\title{
Anatomy of Trabeculae Lumbar Vertebrae On a Bats (Megachiroptera)
}

\author{
Alfi Hidayah*, Alif Nailil Muna AR, Agatha Yolanda Chirstanty, Muhammad Jafar Luthfi \\ Biological Education Departmen, Faculty of Science and Technology, UIN Sunan Kalijaga \\ Jl. Marsda Adisutjipto No. 1 Yogyakarta 55281, Indonesia. Telp. +62-274-540971, Fax. +62274519739 \\ Email*: Alfihidayah5@gmail.com
}

\begin{abstract}
Bats are the only mammals that can fly. Because of their ability to fly, making the tension received by the bat's spine comes from the front and back.Spongy bone, also known as cancellous bone or trabecular bone, is a very porous type of bone found in animals. It is highly vascularized and contains red bone marrow. Spongy bone is usually located at the ends of the long bones (the epiphyses), with the harder compact bone surrounding it. It is also found inside the vertebrae, in the ribs, in the skull and in the bones of the joints. Spongy bone is softer and weaker than compact bone, but is also more flexible. It is characterized by a lattice-like matrix network called trabeculae (Latin for little beam) that gives it its spongy appearance. Observation of trabeculae can be done by removing the flesh, muscles, and all the tissues attached to the lumbar vertebrae bone. Then the lumbar vertebrae was sanded and to know the anatomy of the trabeculae, it was done by observing the lumbraris vertebrae using a binocular microscope and taking pictures using a camera. Then the structure is analyzed. The observations showed that the anatomical structure of the lumbar vertebrae trabeculae in bats are stressed by tension must be withstood, a ligament being as strong for its weight.
\end{abstract}

Keywords: bats, lumbar vertebrae, trabeculae, pressure, tension

\section{INTRODUCTION}

Bat (Megachiroptera) is a type of mammal that can be found in several tropical regions, including in Indonesia (Arthur, 1972). Bats are the only mammals that can fly. The spine is known as the vertebral columna (Malcolm, 2002). The spinal sequence is a flexible structure formed by a number of bones called vertebrae or vertebrae. Between every two vertebrae there are cartilage pads (Pearce, 2006). The parts of the spine consist of several elements, namely the lumbar vertebrae, sacrum, Coccyx. On the inside of the lumbar vertebrae there are spongy bone or trabecular structures. Curved vertebrae is a structure shaped like a horseshoe, consisting of lamina and pedicles. From this curve appear seven protrusions of the processus, a pair of superior and inferior processes, spinous processes and a pair of tranversal processes. Pedicles are short and are attached to the upper half of the lumbar vertebrae. The lamina is a wide flat structure, located in the medial part of the spinous process. The spinous process itself is a flat, wide, and protruding structure toward the back of the lamina. The transverse process protrudes laterally and slightly posteriorly from the lamina and pedicle connection and together with the spinous process it functions as a lever for the muscles and ligaments that attach to it.

The articular process appears protruding from the lamina. The superior articular process surface is concave and faces medially and slightly posteriorly. The inferior articular process protrudes laterally and is slightly anterior and has a convex surface. (Vitriana, 2013). The function of the spine is generally divided into 2 important parts of each functional unit, namely the static anterior part and the dynamic posterior part. The anterior part which is flexible as a load bearer and absorbs vibrations. Whereas the posterior part consisting of 2 arcus vertebrae, 2 transverse processes, 1 spinous process and 2 facet joints, which serves to protect the neural elements act as fulcrums and direct the movement of a functional unit. This posterior element will divide the compressive load and influence the pattern of spinal movements. (Suyana, 2018). Spongy bone, also known as cancellous bone or trabecular bone, is a very porous type of bone found in animals. It is highly vascularized and contains red bone marrow. The spongy bone is usually located at the ends of the long bones (the epiphyses), with the harder compact bone surrounding it. It is also found in the vertebrae, in the ribs, in the skull and in the bones of the joints. Spongy bone is softer and weaker than compact bone, but is also more flexible. It is characterized by a lattice-like matrix network called trabeculae (Latin for little beam) that gives it its spongy appearance. The structure of trabeculae is composed by cells called osteocytes that sit in small cavities known as lacunae. The lacunae and their accompanying osteocytes are housed in the trabeculae matrix of the bone along with the bone marrow. Blood vessels travel through the harder compact bone to the spongy bone, supplying it with the materials necessary to create blood cells.

Osteocytes positioned close to a blood vessel can take on nutrients and expel waste products through tiny interconnecting channels on the surface of the trabeculae called canaliculi. Spongy bone can be converted to compact bone by the action of osteoblasts, bone cells that secrete the material that creates the compact bone matrix. (Habiba, 2015). The trabeculae of each vertebral 
body have four main trabecular systems with a constant orientation: a vertical trabecular system that runs between the receiving end and sends a vertical load, a horizontal trabecular system that runs on the posterior arch and joins the transversal process, two trabecular systems that are curved obliquely, superior and inferior, starting from the endplates and crossing the pedicle to the spinous process area. This arrangement has the ability to withstand horizontal pressure and friction (Suyana, 2018). Function of trabeculae is storage of bone marrow, site of erythropoiesis, reduces the weight of the skeleton, adds strength and flexibility to bones, and mineral storage. The purpose of this study was to determine the effect of pressure on the anatomical structure of the trabeculae on the bat's spine. This research is very important, because there is no research on the anatomical structure of the trabeculae in the bat's spine.

\section{MATERIALS AND METHODS}

This research uses Megaciroptera to be able to observe the trabeculae, animals are dissected and their stomach contents are removed and then stored in $40 \%$ formalin solution. Next, the vertebrae (lumbar vertebrae) in the upper 3 sections of the caudal section are cut with a surgical instrument. To be able to observe trabeculae by removing the flesh, muscles, and all the tissue attached to the lumbar vertebrae bones using tweezers. Then the lumbar vertebrae was sanded until the middle part was seen. Then the observations were made using a binocular microscope so that the structure of the bat trabeculae was seen on the lumbar vertebrae.

\section{RESULT AND DISCUSSION}

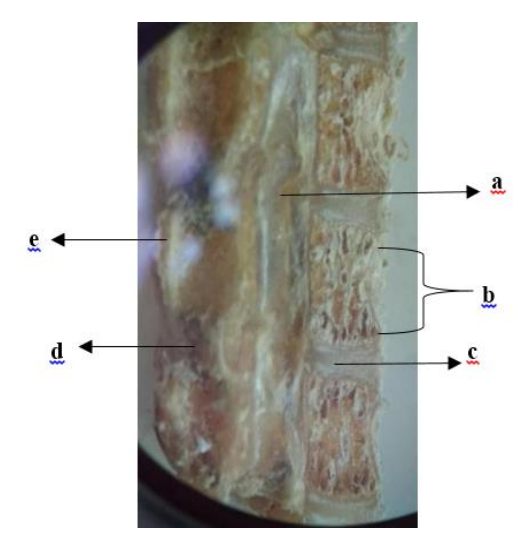

Figure 1. a. Vertebralforamen, b. Trabeculae, c. Intervertebral disc, d. Transverse process, e. Spinous process

The number of bat vertebrae in each species is different. In the bats we observed, the number of vertebrae was 5 . In general, the first lumbar vertebrae are long and wide, becoming shorter and narrower toward the last vertebrae. In this species the spinous processes are low and long in relation to the vertebrae, except in the last vertebrae which reduces its length almoust to one third (Pablo et all, 2017). Based on observations made on the lumbar vertebae of Megachiroptera bats, the results appear to be less dense or loose structures. This can be seen from the presence of cavities or spaces in the trabecular structure. The structure of the trabeculae is a form of adaptation to the presence of pressure and by reducing the weight of the skeleton for added strength and flexibility to bones so the bones function properly and are not damaged. In addition, this is influenced by the force received on the spine. Megaciroptera which is in a horizontal position because bats are animals that carry out their activities by flying. In the flight position causes the pressure received by the bat trabeculae from the front and rear, resulting in horizontal tension in the trabecular structure. This tension causes the structure of the bat trabeculae to have less density compared to some vertebrae in other vertebrates in a vertical position. This is in accordance with the theory According to Muyana (2018) which states that the trabecular bone of each vertebral body has four main trabecular systems with a constant orientation of the vertical trabecular system that runs between the receiving end and sends a vertical load, the horizontal trabecular system that runs on posterior arches and join the transverse process, two oblique curved trabecular systems, superior and inferior, starting from the endplates and crossing in the pedicle to the spinous process area. This arrangement has the ability to withstand horizontal pressure and friction. According to the results of trabecular structure research on the observed Megaciroptera included in the horizontal trabecular system.

\section{CONCLUSION}

Based on observations made on the lumbar vertebae of Megaciroptera bats, the results appear to be less dense or loose structures. This can be seen from the presence of cavities or spaces in the trabecular structure. The structure of the trabeculae is a form of adaptation to the presence of pressure and by reducing the weight of the skeleton for added strength and flexibility to bones so that the bones function properly and are not damaged.

\section{REFERENCES}

Bone marrow. (n.d.). The Free Dictionary - Medical Dictionary. Retrieved Nov 19, 2019 from http://medicaldictionary.thefreedictionary.com/bone+marrow.

Habiba et.al. 2015. Recent origin of low trabecular bone density in modern humans. Proceedings of the National Academy of Sciences. 112(2), 336-371. doi: 10.1073/pnas.1411696112.

Mac Arthur, R H. 1972. Geographical Ecology: Patterns in Distribution of Species. New York: Harper and Row Malcolm 
Slaughter (ed). Basic Concepts in Neuroscience a Student's Survival Guide. New York: Mc Graw-Hill

OpenStax. 2017.Anatomy and Psychology. [online textbook]. Retrieved from https://cnx.org/contents/FPtK1zmh@ 8.81:kwbeYj9S@4/Bone -Structure.

OpenStax. 2017.Anatomy and Psychology. [online textbook]. Retrieved from https://cnx.org/contents/FPtK1zmh@8.81:9SrcxH7k@5/Eryth rocytes
Pearce, Evelyn C. 2006. Anatomi dan Fisiologis Untuk Para Medis, Cetakan kedua puluh sembilan. Jakarta: PT. Gramedia Pustaka Utama

Suyana, I Ketut. 2018. Penyakit Degenerasi Lumbal. Bali: Udayana University Press

Vitriana. 2001. Aspek Anatomi Dan Biomekanik Tulang Lumbo Sakral Dalam Hubungannya Dengan Nyeri Pinggang. SMF Rehabilitasi Medic FK UNPAD 
THIS PAGE INTENTIONALLY LEFT BLANK 